\title{
FISIKA KONTEKSTUAL PEMBANGKIT LISTRIK TENAGA MIKROHIDRO
}

\author{
Richardo Barry Astro1), Hamsa Doa'), Hendro2) \\ 1)Program Studi Pendidikan Fisika, FKIP, Universitas Flores, Ende, Indonesia \\ ${ }^{2)}$ Departemen Fisika, FMIPA, Institut Teknologi Bandung, Bandung, Indonesia \\ Corresponding author : Richardo Barry Astro \\ E-mail : richardobarryastro@gmail.com
}

Diterima 25 Februari 2020, Disetujui 12 April 2020

\begin{abstract}
ABSTRAK
Penelitian ini bertujuan untuk mengetahui prinsip dasar dan sistem kerja pembangkit listrik tenaga mikrohidro (PLTMH) dari sudut pandang fisika sebagai upaya penyediaan dan pengembangan sumber belajar kontekstual. Penelitian ini dilaksanakan menggunakan metode studi literatur, observasi, dan wawancara. Hasilnya ditemukan bahwa PLTMH memiliki tiga komponen utama yakni air sebagai sumber energi, turbin, dan generator. Skema konversi energi pada PLTMH yang menggunakan head adalah sebagai berikut: 1) energi potensial air dari reservoir diubah menjadi energi kinetik pada pipa pesat, 2) energi kinetik air diubah menjadi energi mekanik oleh turbin air, 3) energi mekanik diubah menjadi energi listrik oleh generator. Turbin air berdasarkan prinsip kerja dibagi atas turbin impuls dan turbin reaksi. Turbin impuls memanfaatkan perubahan momentum air sebelum dan setelah menabrak sudu turbin, sedangkan turbin reaksi memanfaatkan perbedaan tekanan pada permukaan sudu. Generator bekerja berdasarkan prinsip induksi elektromagnetik. Ketika rotor generator yang terkopel pada turbin berputar, kumparan konduktor akan memotong garis medan magnet sehingga timbul tegangan induksi.
\end{abstract}

Kata kunci: pembangkit listrik tenaga mikrohidro; konversi energi; turbin, generator.

\begin{abstract}
The research aims to determine the fundamental principles and working systems of Microhydro power plants from a physical standpoint as an effort to provide and develop contextual learning resources. This study was conducted using literature, observation and interview methods. The results found that PLTMH had three main components i.e. water as energy source, turbine, and generator. The energy conversion scheme on PLTMH that uses the head is as follows: 1) The potential energy of water from the reservoir is converted into kinetic energy on the rapid pipeline, 2) water kinetic energy converted into mechanical energy by water turbine, 3) changed mechanical energy into electrical energy by generators. The water turbine based on the working principle is divided into impulse turbines and reaction turbines. The impulse turbine utilizes a change in water momentum before and after crashing the turbine's sudu, while the reaction turbine utilizes pressure differences on the surface of the Sudu. The generators work based on electromagnetic induction principles. When the rotor generator is attached to the turbine spinning, the conductor coil will cut off the magnetic field line so that the induction voltage arises.
\end{abstract}

Keywords: microhydro power plant; energy conversion; turbine; generator.

PENDAHULUAN

Provinsi Nusa Tenggara Timur berdasarkan data Kementerian Energi dan Sumber Daya Mineral pada September 2019 memiliki rasio elektrifikasi (RE) sebesar $74 \%$ (Antaranews.com, 2019b). Namun hasil kajian Universitas Nusa Cendana yang bekerja sama dengan PT PLN pada Oktober 2019 mencatat NTT memiliki RE sebesar 82,97\% (Antaranews.com, 2019a). Terlepas dari perbedaan $\mathrm{RE}$ yang bersumber dari perbedaan metode kajian, NTT adalah provinsi dengan RE terendah di Indonesia. Penyebab utama rendahnya RE di NTT jika dibandingkan dengan rata-rata Nasional yakni sebaran penduduk yang tidak merata dan terpencil, sehingga sangat sulit dijangkau jaringan listrik dari Perusahaan Listrik Negara. Solusi yang diberikan pemerintah dalam upaya meningkatkan RE khususnya di NTT antara lain dengan bantuan lampu tenaga surya hemat energi (LTSHE). Upaya lain yang dapat dilakukan ialah mendorong kemandirian energi memanfaatkan energi baru terbarukan yang dapat dikelola secara swadaya, termasuk pembangkit listrik tenaga mikrohidro (PLTMH).

PLTMH merupakan sumber energi terbarukan yang dapat mengubah energi air 
menjadi energi listrik (Židonis et al., 2015). Pada penerapannya PLTMH dapat memberikan dampak positif berantai mulai dari pemanfaatan energi air dalam skala mikro yang bebas polusi hingga upaya pelestarian daerah aliran sungai dan daerah tangkapan air guna menjaga debit air untuk kelangsungan pasokan energi listrik. Teknologi ini sangat bermanfaat dan dapat diterapkan pada daerah-daerah terisolir yang memiliki potensi dan dikelola secara swadaya. Namun keterbatasan pengetahuan mengakibatkan belum optimalnya penerapan teknologi PLTMH khususnya di NTT. Upaya untuk meningkatkan pengetahuan terkait teknologi mikrohidro dapat dilakukan melalui pembelajaran kontekstual.

Pembelajaran kontekstual merupakan sebuah kegiatan mempelajari gejala/fenomena yang dapat ditangkap oleh panca indera dan terjadi disekitar kita. Pelaksanaan pembelajaran dengan model kontekstual dinilai dapat meningkatkan keaktifan siswa karena menghubungkan muatan akademis dengan gejala atau fenomena yang terjadi di kehidupan sehari-hari (Hakim et al., 2018). Fisika sebagai ilmu yang mempelajari fenomena alam dan interaksi di dalamnya sangat tepat diajarkan menggunakan pembelajaran kontekstual tidak terkecuali pada topik terkait mikrohidro. Hal ini berangkat dari fakta bahwa teknologi mikrohidro dikembangkan dari konsep-konsep fisika. Penelitian ini bertujuan untuk mengetahui prinsip dasar dan sistem kerja pembangkit listrik tenaga mikrohidro dari sudut pandang fisika sebagai upaya penyediaan dan pengembangan sumber belajar kontekstual.

\section{METODE PENELITIAN}

Penelitian ini dilaksanakan dengan metode studi literatur, wawancara, dan observasi. Studi literatur dilakukan dengan mempelajari konsep PLTMH yang mencakup konsep dasar, komponen, dan prinsip kerja pembangkit listrik tenaga mikrohidro dalam perspektif fisika. Kegiatan observasi dilaksanakan pada pabrik dan laboratorium pengembangan mikrohidro CV Cihanjuang Inti Teknik Cimahi. Kegiatan wawancara dalam penelitian ini dilakukan antara lain kepada pakar mikrohidro dari Asosiasi Hidro Bandung dan tenaga ahli CV Cihanjuang Inti Teknik.

\section{HASIL DAN PEMBAHASAN \\ Sejarah Perkembangan Pembangkit Listrik Tenaga Hidro}

Pembangkit listrik tenaga hidro (PLTH) bermula dari kincir air yang terbuat dari kayu dan telah digunakan di Eropa sekitar 2000 tahun silam dan difungsikan dalam penggilingan gandum. Revolusi industri di
Eropa dan kebutuhan untuk mengembangkan perangkat penghasil listrik kecil menyebabkan pengembangan kincir air menjadi turbin listrik. Turbin hidro pertama tercatat dikembangkan oleh Benoit Foureyron di Prancis sekitar tahun 1820an. Pada awal abad ke-20 terjadi peningkatan pemanfaatan PLTH di Eropa dan Amerika Utara yang membangun bendungan serta mengeksploitasi hingga $50 \%$ potensi yang secara teknis memungkinkan (Paish, 2002). PLTH di Indonesia telah ada sejak tahun 1882 untuk industri teh (Sentanu, 2011).

Berdasarkan Peraturan Menteri Pekerjaan Umum dan Perumahan Rakyat Republik Indonesia Nomor 9 Tahun 2016, pembangkit listrik yang memanfaatkan air dikelompokkan menjadi tiga berdasarkan besarnya daya yang dihasilkan yakni pembangkit listrik tenaga air berkapasitas lebih dari 10 megawatt (MW), pembangkit listrik tenaga minihidro berkapasitas antara $1 \mathrm{MW}$ sampai $10 \mathrm{MW}$, dan pembangkit listrik tenaga mikrohidro dengan kapasitas kurang dari $1 \mathrm{MW}$. Kategori small hydro secara sederhana dapat dikelompokkan lagi menjadi beberapa tingkatan, yakni pikohidro berkapasitas kurang dari $1 \mathrm{~kW}$, mikrohidro berkapasitas $1 \mathrm{~kW}$ sampai $100 \mathrm{~kW}$, serta minihidro berkapasitas $100 \mathrm{~kW}$ hingga 1 MW (Sentanu, 2011).

\section{Komponen Pembangkit Listrik Tenaga Mikrohidro}

Desain dan komponen dari PLTMH dapat dibuat bermacam-macam disesuaikan dengan karakteristik dan kondisi wilayah tempat PLTMH tersebut akan dibangun. Secara umum komponen PLTMH terdiri atas bendungan, saluran pembawa, saluran pengendap, saluran penenang, pipa pesat, rumah pembangkit dan saluran pembuangan. Skema PLTMH ditunjukkan pada Gambar 1.

1) Bendungan penyadap (weir) berfungsi untuk menaikkan dan mengontrol tinggi air dalam sungai secara signifikan untuk dialihkan ke sebuah pembuka (intake).

2) Saluran pembawa (head race) dibuat mengikuti kontur bukit untuk menjaga elevasi air.

3) Bak penenang (head tank) berfungsi mengatur perbedaan keluaran air yang akan masuk ke pipa pesat sekaligus digunakan untuk mengendapkan partikel-partikel pasir dari air

4) Pipa pesat (pentstock) dihubungkan pada sebuah elevasi menuju turbin, dan berfungsi untuk mengoptimalkan energi jatuhan air yang akan memutar turbin.

5) Rumah pembangkit (power house) berfungsi untuk menempatkan turbin, generator, dan pusat kendali distribusi listrik. 
6) Saluran pembuang (tail race) berfungsi untuk mengalirkan air yang keluar dari turbin air untuk diteruskan ke sungai.

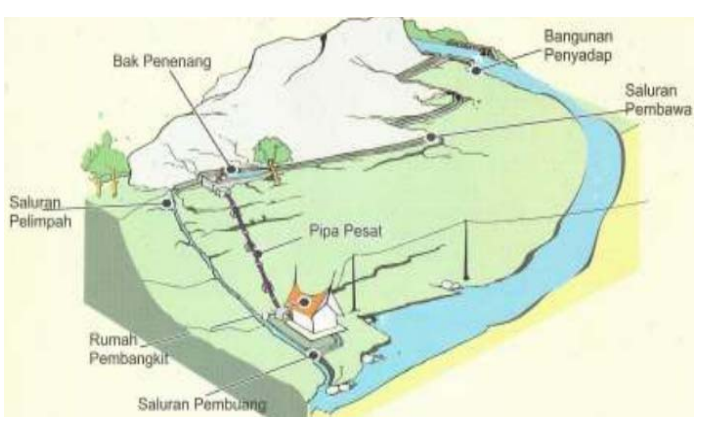

Gambar 1. Skema PLTMH (Gunawan et al., 2014)

\section{Prinsip Dasar Pembangkit Listrik Tenaga Mikrohidro}

PLTMH merupakan sistem pembangkit listrik berskala kecil yang menggunakan air dalam debit yang kecil sebagai sumber penggeraknya. Air yang dapat dimanfaatkan pada teknologi PLTMH dapat bersumber dari saluran irigasi, sungai atau air terjun alam (Bahtiar et al., 2015). Secara umum PLTMH memiliki tiga komponen utama yakni air, turbin air, dan generator. Debit air dan head adalah elemen penting untuk menghasilkan energi berupa energi mekanik maupun listrik (Rompas, 2011). Proses konversi energi pada PLTMH yang menggunakan head dijelaskan sebagai berikut: 1) energi potensial air berubah menjadi energi kinetik pada pipa pesat, 2) energi kinetik diubah oleh turbin menjadi energi mekanik, 3) energi mekanik putaran turbin dikonversi menjadi energi listrik oleh generator.

Head merupakan jarak vertikal atau beda ketinggian antara muka air pada reservoir dengan muka air yang keluar dari turbin air (Hatch Energy, 2008). Ketinggian head dapat dimodifikasi dengan membuat bendungan sederhana. Pada tahap observasi lokasi potensial, pengukuran head dapat dilakukan secara dengan beberapa cara antara lain menggunakan meteran, waterpas, altimeter page pada GPS, maupun menggunakan alat pengukur kemiringan bidang seperti range finder, maupun clinometer yang dikombinasikan dengan pengukuran langsung terhadap kemiringan bidang (Sentanu, 2011).

Semakin besar debit air yang menerobos turbin maka semakin besar pula daya yang dihasilkan. Debit air dipengaruhi oleh curah hujan, keadaan geologi, flora, temperatur, dan sebagainya. Debit air menjadi data pokok dalam perencanaan pembangkit listrik untuk mengetahui potensi daya yang dapat dihasilkan dan penentuan turbin yang sesuai. Beberapa cara pengukuran debit air yakni pengukuran langsung dan pengukuran tidak langsung. Metode pengukuran langsung dilakukan untuk aliran air yang tidak menyebar, berbentuk terjunan/saluran irigasi. Pengukuran langsung dilakukan dengan mencatat debit air yang ditampung dalam sebuah wadah selama selang waktu tertentu. Metode pengukuran tidak langsung terutama dilakukan untuk aliran air yang memiliki bentuk penampang tidak teratur seperti pada selokan dan sungai. Debit air pada pengukuran tidak langsung diperoleh dari perkalian kecepatan rata-rata aliran pada suatu penampang dengan luas penampang pada bagian tersebut berdasarkan persamaan Kontinuitas.

Pengukuran kecepatan aliran air pada arah horizontal dapat dilakukan dengan beberapa cara seperti mengukur waktu tempuh dari sebuah benda yang mengapung (metode apung), dan dapat pula digunakan alat ukur kecepatan air flow meter dan current meter. Pada arah vertikal perhitungan kecepatan air dapat dilakukan menggunakan persamaan Bernoulli dengan memposisikan permukaan reservoir sebagai titik $A$ dan permukaan ujung pipa pesat sebagai penampang $B$. Luas permukaan penampang $A$ jauh lebih besar dibandingkan dengan penampang $B$ sehingga kecepatan air pada penampang $A$ dapat dianggap nol. Tekanan pada penampang $A$ sama dengan tekanan pada penampang $B$ (tekanan atmosfer). Jika acuan pengukuran di titik $B$ maka tinggi penampang $B$ adalah nol dan tinggi penampang $\mathrm{A}$ adalah $\mathrm{H}$ (head). Maka perhitungan kecepatan aliran air di titik $B$ adalah sebagai berikut:

$$
v_{B}=\sqrt{2 g H}
$$

Prinsip sederhana dari PLTMH adalah sebagai berikut: pada sungai dibangun bendungan sederhana yang akan mengalirkan air melalui saluran pembawa menuju bak pengendap, yang dalam banyak kasus berfungsi sekaligus sebagai bak penenang. Sebelum menuju ke pipa pesat, biasanya dipasang penyaring agar kotoran/sampah yang mengapung tidak merusak turbin. Di dalam pipa pesat, energi potensial air perlahan berubah menjadi energi kinetik sehingga air yang keluar dari pipa pesat tersebut memiliki kecepatan yang besar. Energi jatuhan air tersebut akan menyebabkan turbin berputar (Paish, 2002). Perputaran turbin dapat digunakan untuk memutar sebuah alat mekanikal atau mengoperasikan sebuah generator listrik. Putaran turbin yang dihubungkan dengan generator akan menghasilkan tegangan induksi 
yang dapat disalurkan kepada konsumen. Secara teori daya yang dihasilkan oleh pembangkit listrik tenaga hidro termasuk mikrohidro adalah sebagai berikut (Khomsah \& Zuliari, 2015; Ranjan et al., 2019):

$$
P_{\text {teoritis }}=\rho g Q H
$$

Daya teoritis akan berkurang setelah melalui turbin dan generator dengan nilai efisiensi tertentu. Daya riil keseluruhan sistem PLTMH dapat dituliskan sebagai berikut (Hatch Energy, 2008; Paish, 2002):

$$
P_{\text {ril }}=\eta \rho g Q H
$$

Dengan $\mathrm{P}$ adalah daya terbangkit pada poros turbin (Watt), $\rho$ adalah densitas air $\left(\mathrm{kg} / \mathrm{m}^{3}\right), Q$ merupakan debit air $\left(\mathrm{m}^{3} / \mathrm{s}\right), \mathrm{H}$ adalah ketinggian efektif head turbin $(\mathrm{m})$, dan $\eta$ adalah efisiensi total sistem PLTMH. Efisiensi total sistem yang dimaksud efisiensi keseluruhan sistem PLTMH yang diperoleh melalui persamaan berikut (Okedu et al., 2020):

$$
\eta_{\text {total }}=\eta_{\text {pentstoke }} \cdot \eta_{\text {turbine }} \cdot \eta_{\text {generator }} \cdot \eta_{\text {System }}
$$

\section{Turbin Mikrohidro}

Turbin air berperan untuk mengubah energi air (energi potensial, tekanan, dan energi kinetik) menjadi energi mekanik dalam bentuk putaran poros turbin (Uhunmwangho et al., 2018). Berbagai tipe turbin dikembangkan untuk mengakomodasi berbagai kondisi alam. Terdapat dua jenis turbin berdasarkan prinsip kerjanya yakni turbin impuls dan turbin reaksi (Židonis et al., 2015).

\section{A. Turbin Impuls}

Turbin impuls lahir dari konsep sederhana tentang perubahan momentum yang terjadi sebelum dan setelah air menabrak sudusudu (roda turbin). Sistem kerja turbin impuls ialah menggunakan energi air dari jet penyemprot untuk menabrak sudu dan menyebabkan turbin berotasi (energi mekanik). Sudu pada turbin impuls tidak terendam dan air tetap pada tekanan atmosfer sebelum dan setelah melakukan kontak dengan sudu (Uhunmwangho et al., 2018). Turbin berjenis impuls seperti Pelton, Crossflow, dan Turgo cenderung digunakan pada kondisi head sedang hingga tinggi dan laju aliran rendah (Židonis et al., 2015). Desain sudu turbin jenis impuls dibuat sedemikan rupa untuk memperluas bidang kontak dengan air.

\section{(a)}

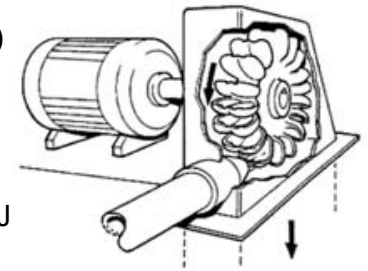

(b)

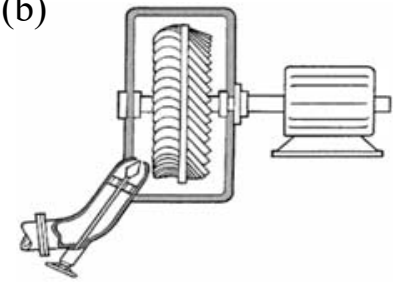

(c)

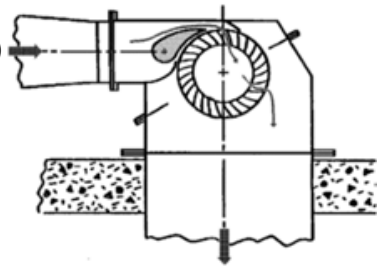

Gambar 2. Turbin impuls: (a) Pelton, (b)

Turgo, dan (c) Crossflow (Paish, 2002)

Sudu-sudu turbin Pelton (Gambar 2a) terdiri atas dua bagian yang simetris. Pembagian sudu turbin Pelton demikian memperbesar gaya kontak terhadap semburan air sehingga hampir semua energi air dari nozzle (jet penyemprot) mendorong sudu dan selanjutnya air dibelokkan jatuh ke saluran pembuangan (Paish, 2002). Sistem turbin Turgo (Gambar 2b) memiliki kemiripan dengan turbin Pelton namun dengan posisi nozzle yang dimiringkan secara aksial. Posisi ini memungkinkan aliran air lebih menyeluruh pada permukaan sudu turbin (Paish, 2002; Židonis et al., 2015). Turbin Turgo dapat menangani tingkat aliran air secara signifikan lebih tinggi dibandingkan turbin Pelton, dan memungkinkan untuk operasi yang lebih efisien dalam rentang head lebih rendah (Cobb \& Sharp, 2013). Turbin Crossflow atau turbin Banki (Gambar 2c) merupakan turbin aliran radial yang bekerja pada tekanan atmosfer sehingga tidak memerlukan penutup kedap udara (Khomsah \& Zuliari, 2015). Turbin Crossflow dapat dioperasikan pada debit dan head yang lebih rendah dibandingkan turbin impuls lainnya. Turbin Crossflow menggunakan nozzle persegi panjang yang lebarnya sesuai dengan lebar sudu. Performa turbin Crossflow dipengaruhi oleh jumlah, sudut, bentuk, dan ketebalan sudu, serta bentuk dan sudut lintasan nozzle (Ranjan et al., 2019).

\section{B. Turbin Impuls}

Turbin reaksi memanfaatkan tekanan dari aliran air untuk memutari sudunya. Turbin reaksi sepenuhnya terendam air dalam permukaan tertutup. Sudu turbin dibentuk agar 
terjadi perbedaan tekanan pada turbin. Tekanan pada bagian atas lebih besar dibanding tekanan di bagian bawah turbin sehingga menyebabkan gaya angkat hidrodinamika yang mendorong sudu berputar (Paish, 2002; Uhunmwangho et al., 2018). Turbin reaksi umumnya digunakan pada kondisi head rendah dengan debit besar Contoh turbin reaksi adalah turbin Francis, dan Propeller/Kaplan (Židonis et al., 2015).

Sudu turbin Propeler (Gambar 3a) berbentuk baling-baling dengan sisi-sisi sudu dibentuk menyerupai sayap pesawat terbang. Turbin Propeler didesain untuk kondisi head rendah dengan debit air besar (Caxaria et al., 2011). Umumnya turbin dengan sudu tetap disebut turbin Propeler, dan jika sudu turbin dapat diatur dinamakan turbin Kaplan (Hatch Energy, 2008). Air masuk ke sudu turbin Kaplan/Propeller secara aksial dan menyebabkan daerah di bawah sudu mengalami penurunan tekanan akibat kecepatan alir yang tinggi. Reaksi atas perbedaan tekanan tersebut menimbulkan gaya angkat. Berputarnya sudu turbin dipengaruhi oleh komponen tangensial dari gaya angkat.

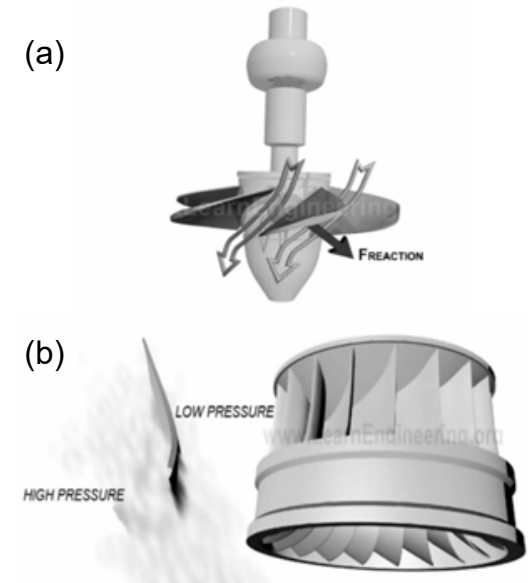

Gambar 3. Sudu turbin reaksi: (a) Kaplan, dan (b) Francis (Mathew, 2018)

Turbin Francis pada dasarnya merupakan modifikasi dari turbin Propeler (Paish, 2002). Air masuk ke dalam sela-sela sudu turbin secara radial dan akan keluar secara aksial. Masing-masing sudu turbin Francis (Gambar 3b) dibentuk menyerupai sayap pesawat terbang yang tipis dan tajam sehingga memungkinkan aliran air pada kedua sisi sudu berbeda. Sisi dengan aliran air besar akan kekurangan tekanan sehingga tercipta gaya angkat yang mendorong sudu ke sisi tersebut. Penampang bawah sudu turbin Francis sengaja dibuat melengkung agar air yang keluar dari sela-sela sudu turbin secara aksial menabrak lengkungan tersebut dan menghasilkan perubahan momentum (Mathew, 2018). Dengan demikian turbin Francis merupakan kombinasi antara turbin impuls dan turbin reaksi.

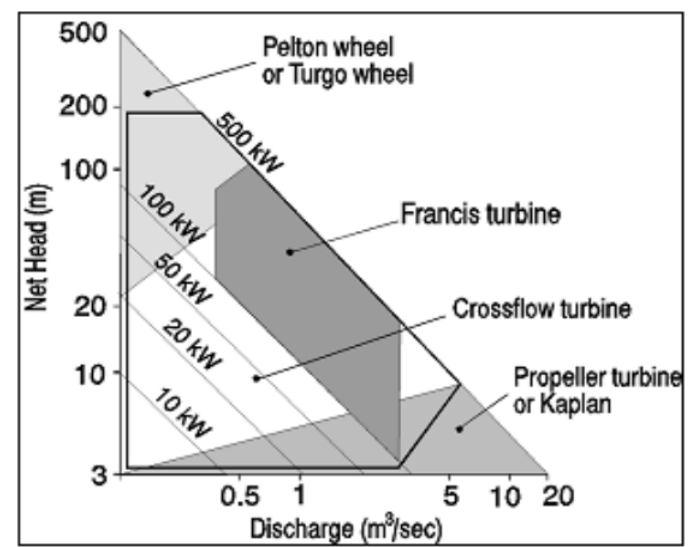

Gambar 4. Grafik hubungan head dan debit air untuk turbin mikrohidro (Paish, 2002)

Gambar 4 menunjukkan turbin impuls (Pelton dan Turgo) dapat beroperasi pada head medium dan tinggi dengan debit air kecil. Namun turbin impuls lainnya yakni Crossflow dapat pula diterapkan pada kondisi head yang sangat rendah. Sebaliknya turbin reaksi umumnya digunakan pada kondisi head rendah. Turbin Propeller/Kaplan dapat bekerja optimal pada head rendah dengan debit air yang cukup besar. Adapun turbin Francis dapat beroperasi pada head rendah hingga medium. Hidro turbin terbaik memiliki efisiensi antara $80 \%$ hingga lebih dari $90 \%$, dan akan berkurang seiring berkurangnya ukuran turbin. Efisiensi turbinturbin mikrohidro cenderung berada pada kisaran $60 \%$ - 80\% (Paish, 2002).

\section{Generator Listrik}

Generator merupakan bagian dari pembangkit listrik yang mengubah energi mekanik seperti putaran turbin hidro menjadi energi listrik. Umumnya pembangkit listrik tenaga hidro berskala kecil menggunakan generator AC karena daya yang dihasilkan dapat dipakai untuk memasok berbagai peralatan listrik AC (Basar \& Othman, 2013; ESHA, 2004). Komponen utama dari generator adalah rotor dan stator. Rotor merupakan bagian yang berputar dikopel dengan poros turbin sebagai tenaga putarnya. Stator merupakan bagian generator yang tidak bergerak. Prinsip dasar generator menggunakan hukum Faraday yang menyatakan bahwa jika terjadi perubahan garis gaya magnet pada sebuah kumparan kawat, 
maka akan timbul gaya gerak listrik (GGL) induksi pada kawat (Breeze, 2018).

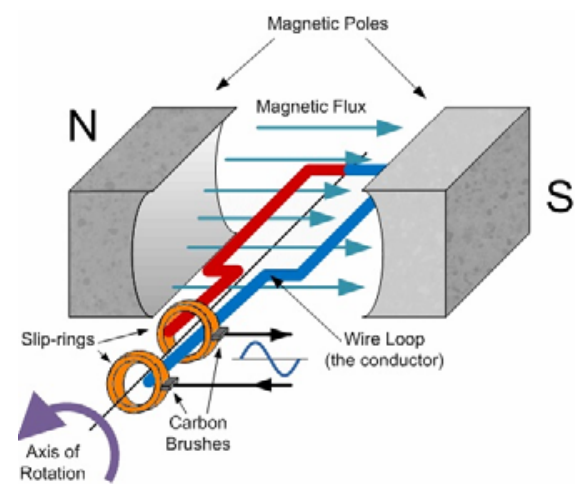

Gambar 5. Komponen generator AC (Sinusoidal Waveforms, n.d.)

Generator AC bekerja berdasarkan prinsip induksi elektromagnetik. Komponenkomponen generator AC (Gambar 5) meliputi rotor berupa kawat konduktor (wire loop), cincin logam (slip ring) yang terhubung pada konduktor, sedangkan stator terdiri atas dua buah magnet permanen berbeda kutup yang saling berhadapan dan sikat karbon yang menyentuh slip ring yang berfungsi mengalirkan arus listrik dari konduktor ke luar generator. Ketika rotor yang terkopel pada turbin berputar maka kawat konduktor akan memotong flux sehingga timbul GGL pada konduktor tersebut.

Generator generasi terdahulu memiliki sebuah kumparan yang berputar di dalam medan magnet stasioner yang berasal dari magnet permanen seperti pada Gambar 8 . Namun desain ini memiliki efisiensi yang rendah terutama jika digunakan pada pembangkit listrik besar, termasuk pembangkit listrik tenaga air (Breeze, 2018). Beberapa generasi generator menempatkan magnet permanen sebagai rotor yang berputar pada sebuah kumparan konduktor yang diam (stator). Generasi terbaru mengganti magnet permanen pada rotor dengan menempatkan kumparan elektromagnetik yang menghasilkan medan magnet saat dihubungkan dengan arus DC dari generator sekunder (self-excitation). Medan magnet ini akan menginduksi arus dalam kumparan stator. Pada generator 1 fasa yang hanya memiliki dua kutub magnet (utaraselatan) arus yang dihasilkan pada kumparan adalah arus AC yang bervariasi dalam satu siklus $360^{\circ}$ untuk setiap satu putaran rotor. Dengan demikian untuk memperoleh standar frekuensi listrik $A C(50 \mathrm{~Hz}-60 \mathrm{~Hz})$ maka rotor harus berputar dengan frekuensi relatif tinggi, yakni antara 3000 rpm - 3600 rpm (revolutions per minute).
Salah satu upaya untuk dapat meningkatkan kecepatan putar rotor ialah membuat sambungan turbin dan rotor pada generator melalui serangkaian roda gigi. Namun mekanisme sambungan demikian akan menurunkan efisiensi sistem turbin-generator (Breeze, 2018). Solusi yang dapat ditempuh ialah menambahkan pasangan kutub magnet pada generator sehingga rotor beroperasi dengan frekuensi yang lebih rendah. Jika jumlah kutub magnet digandakan menjadi enam, maka akan ada tiga siklus AC untuk setiap putaran rotor. Dengan demikian rotor hanya perlu berputar pada frekuensi 1000 rpm - 1200 rpm. Semakin banyak pasangan kutub pada generator maka semakin kecil frekuensi putar rotor yang diperlukan (Breeze, 2018). Solusi lain untuk memperkecil frekuensi putar rotor ialah dengan menambah kumparan konduktor pada stator sehingga dalam satu putaran akan timbul tegangan induksi pada masing-masing kumparan yang besarnya sama namun berbeda fasa. Generator yang memakai tiga kumparan menghasilkan ggl induksi sama besar namun dengan beda fasa sebesar $120^{\circ}$ pada masing-masing kumparan yang dikenal sebagai generator 3 fasa.

\section{Sistem Transmisi Mekanik}

Transmisi mekanik adalah komponen yang menghubungkan antara turbin dan generator. Sambungan antara turbin dan generator menggunakan prinsip hubungan roda-roda yakni: roda-roda seporos pada sambungan langsung dan roda-roda yang dihubungkan dengan sabuk/roda gigi. Sambungan langsung umumnya memakai satu poros untuk turbin dan generator seperti pada turbin Pelton dan Turgo. Hubungan turbin dan generator sepusat mengindikasikan kecepatan sudut turbin dan generator sama (ESHA, 2004).

Sambungan memakai sabuk maupun roda gigi mengindikasikan adanya kesamaan kecepatan tangensial antara turbin dan generator, sedangkan kecepatan sudut keduanya berbeda. Untuk itu diperlukan transmisi mekanik dengan menyesuaikan rasio gear pada turbin maupun pada generator untuk menghasilkan putaran yang diperlukan generator. Contoh sambungan demikian adalah turbin jenis Crossflow.

\section{SIMPULAN DAN SARAN Simpulan}

Pembangkit listrik tenaga mikrohidro memiliki tiga komponen dasar yakni aliran air, turbin, dan generator. Energi potensi jatuhan air berubah menjadi energi kinetik pada pipa pesat dan selanjutnya diubah menjadi energi mekanik 
oleh turbin. Berdasarkan prinsip kerjanya turbin terbagi atas turbin impul yang memanfaatkan konsep perubahan momentum air sesaat sebelum dan setelah menabrak sudu, dan turbin reaksi yang memanfaatkan perbedaan tekanan saat aliran air melewati sudu. Turbin impuls umumnya diterapkan pada kondisi head tinggi dengan debit aliran rendah, sedangkan turbin rekasi umunya dipasang pada kondisi head rendah dengan debit aliran tinggi. Generator berfungsi mengubah energi mekanik turbin menjadi energi listrik berdasarkan prinsip induksi elektromagnetik. Sambungan antara turbin dan generator menggunakan konsep roda-roda, antara lain sambungan langsung seperti pada turbin Pelton dan Turgo dan sambungan memakai sabuk/roda gigi seperti pada turbin Crossflow.

Teknologi pembangkit listrik tenaga mikrohidro (PLTMH) menggunakan banyak konsep fisika sebagaimana yang diuraikan pada makalah ini. Dengan demikian maka sangat laik jika PLTMH digunakan sebagai salah satu pembelajaran kontekstual terutama pada daerah-daerah yang telah memiliki teknologi ini dalam upaya meningkatkan pemahaman dan penguatan konsep fisika. Pembelajaran fisika kontestual PLTMH juga dapat diterapkan pada daerah dengan potensi energi air yang cukup namun memiliki rasio elektrifikasi yang rendah seperti di NTT dalam upaya peningkatan literasi sains dan mewujudkan kemandirian energi.

\section{Saran}

Perlu ada penelitian lanjutan untuk menggali penerapan konsep fisika PLTMH pada tataran yang lebih teknis dan spesifik.

\section{UCAPAN TERIMA KASIH}

Penulis mengucapkan terima kasih kepada Insinyur Sentanu Hindrakusuma dari Asosiasi Hidro Bandung dan CV Cihanjuang Inti Teknik atas pengetahuan dan ilmu yang dibagikan.

\section{DAFTAR RUJUKAN}

Antaranews.com. (2019a, Oktober 28). Rasio elektrifikasi NTT capai 82,97 persen per Oktober 2019. Diakses pada 2 Februari 2020, dari https://www.antaranews.com/ berita/1135008/rasio-elektrifikasi-nttcapai-8297-persen-per-oktober-2019

Antaranews.com. (2019b, November 4). Rasio elektrifikasi nasional capai 98,86 persen. Diakses pada 2 Februari 2020 pada

https://www.antaranews.com/berita/11 45880/rasio-elektrifikasi-nasional- capai-9886-persen

Bahtiar, A., Hidayat, D., M., \& J.M., Syakir, N and Wibawa, B. . (2015). Aplikasi Pembangkit Listrik Mikrohidro Untuk Penerangan Lingkungan Masyarakat Di Kecamatan Ciwidey Kabupaten Bandung. Jurnal Aplikasi Ipteks Untuk Masyarakat, 4(1), 15-17.

Basar, M. F., \& Othman, M. M. (2013). An Overview of the Key Components in the Pico Hydro Power Generation System Faculty of Engineering Technology. Latest Trends in Renewable Energy and Environmental Informatics, 206213.

Breeze, P. A. (2018). Hydropower Generators. In Hydropower (1st ed., pp. 47-52). Academic Press.

Caxaria, G. A., de Mesquita e Sousa, D., \& Ramos, H. M. (2011). Small Scale Hydropower: Generator Analysis and Optimization for Water Supply Systems. Proceedings of the World Renewable Energy Congress - Sweden, 8-13 May, 2011, Linköping, Sweden, 57, 13861393.

Cobb, B. R., \& Sharp, K. V. (2013). Impulse (Turgo and Pelton) turbine performance characteristics and their impact on picohydro installations. Renewable Energy, 50, 959-964.

ESHA. (2004). Guide on How to Develop a Small Hydropower Plant. European Small Hydropower Association, 296. Diakses pada 10 Februari 2020, dari http://citeseerx.ist.psu.edu/viewdoc/do wnload?doi=10.1.1.172.1731\&rep=rep $1 \&$ type $=p d f$

Gunawan, A., Oktafeni, A., \& Khabzli, W. (2014). Pemantauan Pembangkit Listrik Tenaga Mikrohidro (PLTMH). Jurnal Rekayasa Elektrika, 10(4), 28-36.

Hakim, S., Wahyudi, W., \& Verawati, N. N. S. P. (2018). Pengaruh Model Pembelajaran Contextual Teaching and Learning (CTL) Berbantuan LKS terhadap Hasil Belajar Fisika Siswa SMA Attohiriyah Bodak. Lensa: Jurnal Kependidikan Fisika, 6(1), 1.

Hatch Energy. (2008). Low Head Hydro Market Assessment (Vol. 1, Issue March).

Khomsah, A., \& Zuliari, E. A. (2015). Analisa Teori: Performa Turbin Cross Flow Sudu Bambu 5 " sebagai Penggerak Mula Generator Induksi 3 Fasa. Seminar Nasional Sains Dan Teknologi Terapan, 1, 79-88.

Mathew, S. (2018). How does Francis Turbine work? diakses pada 11 Februari 2020, 
dari Learn Engineering The Virtual University

https://www.learnengineering. org/howdoes-francis-turbine-work.html

Peraturan Menteri Pekerjaan Umum dan Perumahan Rakyat Republik Indonesia Nomor 9 Tahun 2016 tentang Tata Cara Pelaksanaan Kerjasama Pemerintah dan Badan Usaha dalam Pemanfaatan Insfrastruktur Sumber Daya Air untuk Pembangunan Pembangkit Listrik Tenaga Air. Jakarta: Kementerian PUPR.

Okedu, K. E., Uhunmwangho, R., \& Odje, M. (2020). Harnessing the potential of small hydro power in Cross River state of Southern Nigeria. Sustainable Energy Technologies and Assessments, 37(December 2019), 100617.

Paish, O. (2002). Small hydro power: Technology and current status. Renewable and Sustainable Energy Reviews, 6(6), 537-556.

Ranjan, R. K., Alom, N., Singh, J., \& Sarkar, B. K. (2019). Performance investigations of cross flow hydro turbine with the variation of blade and nozzle entry arc angle. Energy Conversion and Management, 182(May 2018), 41-50.

Rompas, P. T. D. (2011). Analisis Pembangkit Listrik Tenaga Mikrohidro (Pltmh) Pada Daerah Aliran Sungai Ongkak Mongondow Di Desa Muntoi Kabupaten Bolaang Mongondow. 16(2).

Sentanu, H. (2011). Pembangkit Listrik Tenaga Mikrohidro. Seminar on Electric, Informatics and It's Education.

Sinusoidal Waveforms. (n.d.). Electronics Tutorials. Diakses pada 21 February 2020,

dari https://www.electronicstutorials. ws/accircuits/sinusoidal-waveform.html

Uhunmwangho, R., Odje, M., \& Okedu, K. E. (2018). Comparative analysis of mini hydro turbines for Bumaji Stream, Boki, Cross River State, Nigeria. Sustainable Energy Technologies and Assessments, 27(September 2017), 102-108.

Židonis, A., Benzon, D. S., \& Aggidis, G. A. (2015). Development of hydro impulse turbines and new opportunities. Renewable and Sustainable Energy Reviews, 51, 1624-1635. 